\title{
Photosynthetic efficiency and rapid light curves of sediment-biofilms along a water quality gradient in the Great Barrier Reef, Australia
}

\author{
Sven Uthicke* \\ Australian Institute of Marine Science, PMB No. 3, Townsville, Queensland 4810, Australia
}

\begin{abstract}
The use of pulse-amplitude modulated (PAM) fluorometry in situ and in vivo as an indicator for nutrient and light status of microphytobenthos communities was investigated on the Great Barrier Reef. The 10 reefs investigated were located along a previously described water quality gradient, confirmed by sediment chemistry parameters $\left(\mathrm{C}_{\text {org }}, N\right)$ and incident light measurements. Estimates of the efficiency of Photosystem II (PSII) were biased when not corrected for background fluorescence that increased with increasing inorganic C content of the sediments. Uncorrected values mimicked a decline in quantum efficiency towards areas with presumed lower nutrient levels. Upon correction, maximum and effective quantum efficiency (ca. 0.59) did not vary significantly along the gradient. The maximum quantum efficiency $\left(\mathrm{F}_{\mathrm{v}} / \mathrm{F}_{\mathrm{m}, \text { corr }}\right)$ measured after dark-adaptation did not differ statistically from effective quantum efficiency in the field $\left(\phi_{\mathrm{PSII}, \mathrm{corr}}\right) . \mathrm{F}_{0}$ values measured in the laboratory were much lower than in situ F readings, indicating a higher concentration of biomass on the surface of the sediment in the field. Rapid light curve parameters (initial slope $\alpha$, relative electron transport rate at light saturation $\mathrm{rETR}_{\max }$, irradiance at onset of light saturation $\mathrm{E}_{\mathrm{k}}$ ) were lower during in vitro readings than in situ. $\mathrm{rETR}_{\max }$ and $\alpha$ values exhibited no statistical differences along the gradient. In contrast, $\mathrm{E}_{\mathrm{k}}$ increased towards midshelf reefs and correlated with incident PAR, indicating that microphytobenthos communities were highly adapted to incident light conditions. Because coral reef microphytobenthos was previously shown to be nitrogen limited, it was unexpected that efficiency measurements would not vary. It is hypothesised that, due to potential for differential vertical migration, the actual species involved in photosynthesis at a given time are nutrient sufficient. Higher nutrient supply may change the community composition on the surface to dominance by species with higher productivity.
\end{abstract}

KEY WORDS: PAM $\cdot$ WQ gradient $\cdot$ Benthic microalgae $(B M A) \cdot$ Nutrient limitation $\cdot$ Light limitation

\section{INTRODUCTION}

Long term monitoring data suggest a decline in coral cover on a world wide scale (Pandolfi et al. 2003). The potential causes for this can range from a variety of disturbances such as from overfishing, global warming and crown-of-thorns outbreaks to nutrient increase and sediment/turbidity. On the Great Barrier Reef of Australia, overall coral cover has declined over the last 50 yr (Pandolfi et al. 2003). Specifically, near-shore reefs in areas of high runoff appear to only recover slowly from disturbance, resulting in reduced coral cover and diversity when compared to reefs further from the mainland or along nutrient and turbidity gradients (e.g. van Woesik et al. 1999, Fabricius et al. 2005).

The fact that nutrient and sediment inputs into the Great Barrier Reef have increased several-fold since European settlement on the north-eastern coast of Australia (Furnas 2003, Alongi \& McKinnon 2005) is now generally accepted among scientists and managers. However, whether this increase has a measur- 
able negative impact on coral reef ecosystems affected by enhanced nutrient, increased sedimentation and decreased light availability is debated (see review by Fabricius 2005). Due to the complexity of nutrient pathways in the ecosystem, experimental approaches often produced ambiguous results depending on the parameters investigated. The largest of these experiments, ENCORE (Enrichment on Coral Reefs, Koop et al. 2001), demonstrated that some reproductive parameters of corals were markedly influenced by nutrient $(\mathrm{N}$ and $\mathrm{P}$ ) enhancement, suggesting reduced coral recruitment that in the long term may lead to declines in the community or failure of recovery from disturbances. However, many other parameters showed no response to N or P additions. Similarly, a study of coral, fish and algal communities along water quality gradients had clear gradient effects on a variety of parameters and composition of several taxonomic groups, whereas effects on several other parameters could not be demonstrated (Fabricius et al. 2005).

Microphytobenthos communities potentially contribute 30 to $40 \%$ of the production on coral reefs (Sorokin 1993). However, the use of these communities as indicators for changing water quality on coral reefs has not been investigated, despite fulfilling several important pre-requisites as ideal indicators: (1) these communities are ubiquitous and easily accessible, because up to $40 \%$ of individual reefs can be sediment covered and is therefore suitable habitat (Uthicke \& Klumpp 1998); (2) several studies have indicated that these communities are $\mathrm{N}$-limited and respond rapidly to increased nutrient levels with increases in biomass and production (Uthicke \& Klumpp 1998, Uthicke 2001, Dizon \& Yap 2003); (3) microphytobenthos also rapidly responds to changes in light condition with adaptations in photo-physiology (Uthicke \& Klumpp 1998).

In planktonic microalgae, the quantum efficiency of Photosystem II (PSII) was suggested as a rapid indicator for nutrient limitation for both $\mathrm{N}$ and $\mathrm{P}$ (e.g. Geider et al. 1993, Beardall et al. 2001), although earlier methodology (e.g. blocking electron transport with 3-(3,4-dichlorophenyl)-1,1-dimethylurea [DCMU] or the 'pump and probe' method, Falkowski \& Raven 1997) made it difficult to measure this parameter in situ. Development of pulse-amplitude modulated (PAM) fluorometers (Schreiber et al. 1986) and specifically commercially available underwater units greatly facilitated in situ measurements. PAM fluorometry allows rapid assessments of the minimum fluorescence

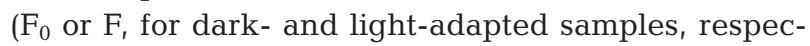
tively) and maximum fluorescence $\left(F_{m}\right.$ or $\left.F_{m}{ }^{\prime}\right)$. These parameters can be used to calculate maximum quantum efficiency and effective quantum efficiency of PSII. A variety of marine primary producers (e.g. seagrasses, Ralph et al. 1998; dinoflagellate symbionts in corals, Ralph et al. 1999; sea ice microalgae communities, Kühl et al. 2001) have now been investigated with direct underwater measurements using PAM.

Data on the photophysiology and nutrient dynamics of marine microphytobenthos are sparse. Most data on quantum efficiency in these communities were derived from PAM measurements either on sediment cores, cultures, or from intertidal mud flats during low tide (Hartig et al. 1998, Kromkamp et al. 1998, Barranguet \& Kromkamp 2000, Serôdio et al. 2001, Perkins et al. 2001, 2002, Glud et al. 2002, Serôdio 2003). Additionally, most of these data are from temperate areas to arctic regions, with only 1 study available from coral reef environments (Underwood 2002). To my knowledge, no in situ PAM measurements of microphytobenthos on tropical carbonate sediments exist.

A second advantage of PAM fluorometry is that light-dependent electron transport as a proxy for productivity can be estimated using rapid light curves (RLCs). These allow estimation of light curve parameters similar to those used in 'classical' productionirradiance $(P-E)$ curves obtained with other methods such as oxygen respirometry or $\mathrm{C}$ uptake. However, although the plot of electron transport rates versus irradiance obtained through RLCs resembles that of $P-E$ curves, these 2 methods must be interpreted differently. The main difference is that RLCs reflect the immediate short term light history, and that $P$ - $E$ curves are measured under steady-state conditions for each light step, which is not achieved with RLCs (White \& Critchley 1999, Ralph \& Gademann 2005).

Here, the use of in situ and in vitro PAM fluorometry as an indicator for nutrient and light status of biofilm communities on coral reef sediments was investigated. To achieve this, the effective quantum efficiency of PSII and RLCs were measured in situ on 10 coral reefs along a water quality gradient described in a longterm chlorophyll study (Brodie et al. in press), which partially overlaps with a previously described gradient (van Woesik et al. 1999). Subsequently, the maximum quantum efficiency was measured after darkadaptation on board a research vessel, and RLCs from each location were repeated onboard to test if comparable results can be obtained after disturbance on samples during transport. Thus, statistical analyses tested for differences of means of various parameters between in situ and onboard measurements, and along the presumed water quality gradient. Because early results of this study indicated that correct measurements of fluorescent parameters on carbonate sediments were hindered by a variable amount of background fluorescence of the sediment not caused by chlorophyll of the plant communities, additional studies were conducted to develop methods to control for this fluorescence. 


\section{MATERIALS AND METHODS}

Sampling. The Whitsunday region is located in the central sector of the Great Barrier Reef Marine Park World Heritage Area on the Great Barrier Reef (GBR) and is a popular tourist destination. I chose to measure quantum efficiency and RLCs on 10 coral reefs along a water quality gradient, roughly corresponding to the distance from the mouths of the O'Connell and Proserpine rivers. Chlorophyll-monitoring established a decrease of water-column chl a content (averaged over $10 \mathrm{yr}$ ) from $0.49 \mu \mathrm{g} \mathrm{l}^{-1}$ in Zone 1 (see Fig. 1) to $0.37 \mu \mathrm{g}$ $\mathrm{l}^{-1}$ in Zone 2, $0.25 \mathrm{\mu g} \mathrm{l}^{-1}$ in Zone 3 and $0.20 \mathrm{\mu g} \mathrm{l}^{-1}$ in Zone 4 (Brodie et al. in press). Two midshelf reefs were also investigated (Zone 5); although chlorophyll measurements in that area were conducted much less frequently, average values were distinctly lower than in the inshore reefs $\left(0.11 \mathrm{\mu g} \mathrm{l}^{-1}\right)$. Similar to the water column chl a data, van Woesik et al. (1999) measured decreasing turbidity and organic matter in sediments with distance towards the north from the river mouth of the Proserpine and O'Connell rivers, and demon- strated corresponding changes in algal and coral communities. Therefore, although other factors such as bathymetry and local current situations certainly play a role in nutrient availability and turbidity, the gradient investigated here is regarded as representing decreasing exposure to land-based runoff.

The 10 reefs investigated were located in pairs along this gradient, thus roughly representing 5 'exposure zones'. On each reef, 1 sample location on the back reef (sheltered from the prevailing SE trade winds) and 1 on the more exposed front reef was chosen and in situ measurements were conducted during 1 dive at each station. Sampling was conducted during a shipbased field trip in August 2004. One additional experiment testing in situ dark-adaptation was conducted in August 2005 on 3 reefs along this gradient (Deloraine Island, Long Island, and Lindeman Island; Fig. 1) and an additional location in Zone 4 (Edward Island).

Pulse-amplified modulated (PAM) fluorometry. All PAM fluorescent measurements were conducted with a WALZ Diving-PAM, using an $8 \mathrm{~mm}$ fibre-optic cable. A short transparent tube $(6 \mathrm{~mm})$ was fixed to the end

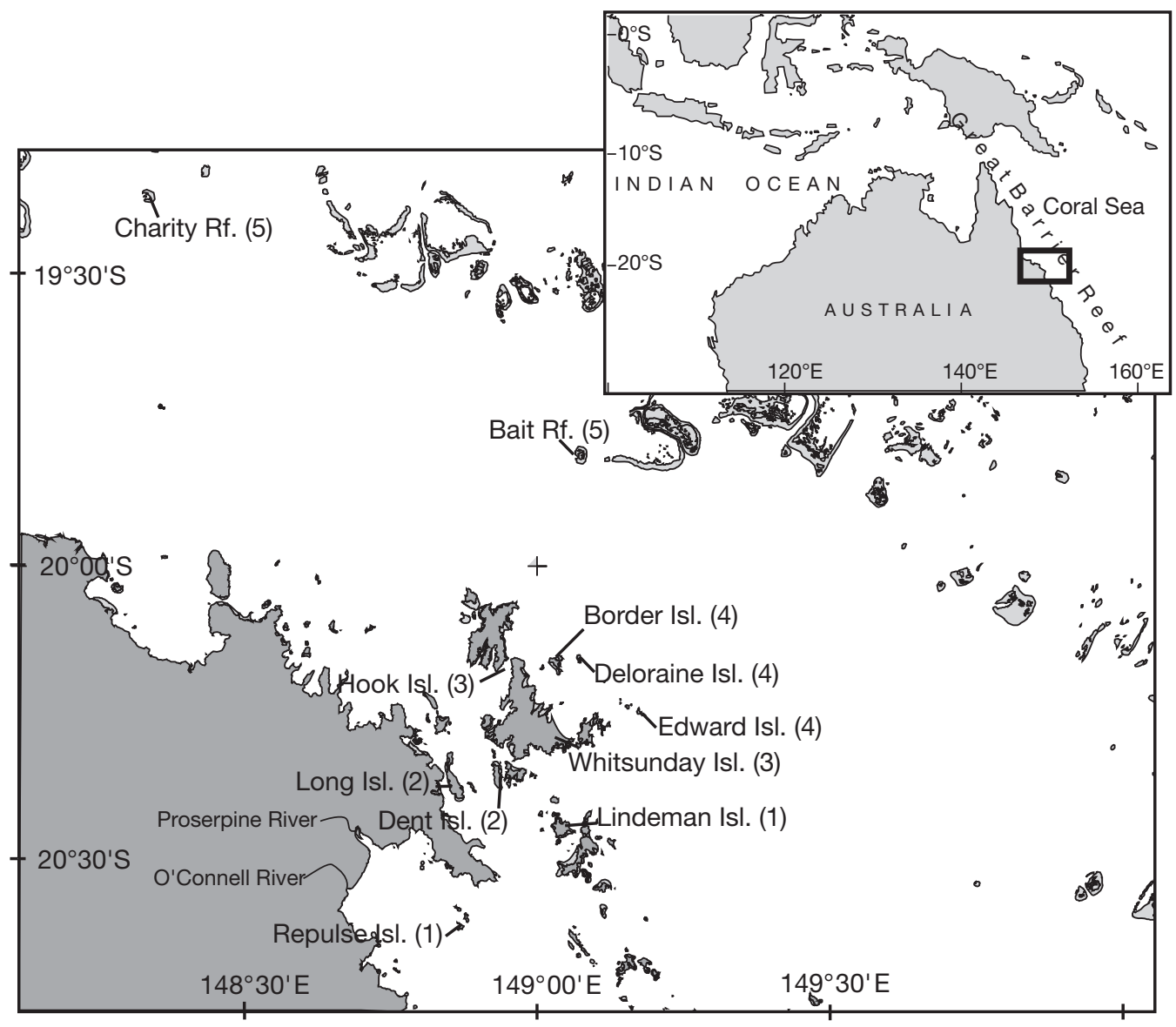

Fig. 1. Locality map showing 10 reefs investigated in the Whitsunday area of the Great Barrier Reef (GBR), Australia. Presumed zones of water quality exposure are given in brackets 
of the fibre-optic cable. The end of this tube rested on the sediment surface to standardise the distance between the sediment surface and the probe. All readings were performed using maximum measuring intensities and output gains.

To have reasonably similar light conditions among locations, early morning and late afternoon dives were avoided, as were dives during the midday-period. Thus, all measurements were conducted between 08:30 and 10:00 h, and 14:00 and 16:00 h. I defined a sediment area between 6 and $8 \mathrm{~m}$ depth as a standard location at each station. This depth was generally at the transition between reef slope and the surrounding sedimentary seafloor. However, at some sites, a slightly deeper location was chosen because sediment did not occur in shallower waters.

At each of these locations, approximately 20 readings of the effective quantum efficiency of PSII were conducted in a haphazard fashion on several sediment patches. In addition, 3 RLCs were conducted at each location. After initial tests on the first reef visited, all light curves were conducted using the same light intensities spanning from 0 to $750 \mu$ mol photon $\mathrm{m}^{-2} \mathrm{~s}^{-1}$.

Dark-adapted readings were required to estimate the maximum quantum efficiency of PSII. Due to time constraints during dives in situ dark-adapted readings were not considered practicable, and the advantages and disadvantages of these were investigated by comparing in situ readings to readings obtained after the dive in the laboratory. However, additional experiments were conducted to evaluate the possibility of in situ dark-adaptation of the sediment communities. These experiments were conducted on 4 reefs at 2 locations each (see above). To achieve this, three $200 \mathrm{ml}$ black polystyrene containers were carefully placed upside down on the sediment community at each location. Containers had a hole drilled (closed with a bung during dark-adaptation) for insertion of the PAM fibre-optic cable. Five F measurements were taken in each container at the beginning of the incubation period ('0 min dark-adaptation'), and $5 \mathrm{~F}_{0}$ readings taken after 15 min dark-adaptation. Just prior to the second readings, 15 readings were also taken on the surrounding sediment.

To obtain dark-adapted in vitro readings, 4 sediment samples were collected with cut-off $60 \mathrm{ml}$ syringes as micro-corers from each location. On shipboard, the top $1 \mathrm{~cm}$ of each sample was transferred into a $50 \mathrm{ml}$ Falcon tube and fresh seawater added. These tubes were dark-adapted for $30 \mathrm{~min}$ at about ambient temperature before conducting 5 readings of maximum quantum efficiency of PSII. To test if in situ-measured RLCs represented short-term adaptations in light curve parameters, RLC readings were also repeated under standardised laboratory conditions. Therefore, 3 RLC measurements were taken in each tube subsequent to the maximum quantum efficiency measurements and re-adaptation to low light (5 to $10 \mu \mathrm{mol}$ photon $\mathrm{m}^{-2} \mathrm{~s}^{-1}$ ) for $10 \mathrm{~min}$. The water was then decanted and tubes frozen for pigment, organic and inorganic $\mathrm{C}$ and $\mathrm{N}$ analysis.

During all in situ PAM readings, incident irradiance was measured with a fibre-optic Diving-Li light sensor (Walz) connected to the PAM. This light sensor was frequently calibrated against a Li-Cor 192SB light sensor.

Quantum efficiency and electron transport rate calculations. Some confusion exists regarding the terminology of parameters used for quantum efficiency and RLCs. Here, I use definitions similar to those given in Barranquet \& Kromkamp (2000), Serôdio et al. (2001) and Ralph \& Gademann (2005). Thus, the maximum quantum efficiency $\left(\mathrm{F}_{\mathrm{v}} / \mathrm{F}_{\mathrm{m}}\right.$, also termed maximum energy conversion efficiency or quantum yield of PSII) of dark-adapted samples is given as the ratio of the variable fluorescence $\left[F_{\mathrm{V}}\right.$, calculated as the difference between the maximum fluorescence $\left(\mathrm{F}_{\mathrm{m}}\right)$ and the minimum fluorescence $\left(F_{0}\right)$ ] over $F_{m}$. The effective quantum efficiency of PSII ( $\left.\phi_{\text {PSII }}\right)$ in light-adapted samples is calculated from $\Delta \mathrm{F}$ [difference between the maximum fluorescence under ambient light $\left(\mathrm{F}_{\mathrm{m}}{ }^{\prime}\right)$ and the minimum fluorescence under the same conditions $(\mathrm{F})]$ divided by $\mathrm{F}_{\mathrm{m}}$ '.

Sediments may contain a certain amount of background fluorescence (Serôdio et al. 2001, Serôdio 2003) that may effect quantum efficiency and relative electron transport rate calculations. Because this has never been tested on calcareous sediments, it was decided to measure background fluorescence in the present study and tests its effect on efficiency calculations.

Average background fluorescence (termed $\mathrm{F}_{0 \text {, sed }}$ in Serôdio 2003) was thus measured for sediments from each location. This was achieved by using samples collected for dark-adapted readings and the chlorophyll analysis. After ethanol extraction (as described below), samples were dried $\left(24 \mathrm{~h}, 60^{\circ} \mathrm{C}\right)$ and subsequently autoclaved in seawater for $2 \mathrm{~h}$ at $120^{\circ} \mathrm{C}$.

Subsequent re-extractions of 10 test samples indicated no measurable amounts of chlorophyll in sediments thus treated.

Once results indicated that background fluorescence was indeed significant (see below), $F_{0, \text { sed }}$ was subtracted from minimum $\left(\mathrm{F}_{0}\right.$ and $\left.\mathrm{F}\right)$ and maximum $\left(F_{m}\right.$ and $\left.F_{m}{ }^{\prime}\right)$ fluorescence prior to analyses of these parameters and calculation of corrected maximum $\left(\mathrm{F}_{\mathrm{v}} / \mathrm{F}_{\mathrm{m}, \mathrm{corr}}\right)$ and effective $\left(\phi_{\text {PSII,corr }}\right)$ quantum efficiency of PSII.

Effective quantum efficiency measurements obtained during the RLC can be used to calculate photosynthetic production expressed as electron transport 
rates. However, in the case of microphytobenthos, the chl a specific absorbance coefficient is difficult to determine (Underwood 2002) and cannot be assumed as a constant because of vertical migration into the sediment and associated changes in biomass involved in photosynthesis (Serôdio 2003). Therefore, it is more appropriate to report relative electron transport rates (rETR), calculated as:

$$
\mathrm{rETR}=\phi_{\mathrm{PSII}, \mathrm{corr}} \times \mathrm{PAR}
$$

for each PAR (photosynthetic active radiation) applied during the measurements.

Background fluorescence. To obtain further information on the source of the background fluorescence, measurements of pure $\mathrm{CaCO}_{3}$ and $\mathrm{MgCO}_{3}$ (Sigma) and a variety of carbonate organisms deemed to be the main contributors to the carbonate sediments were conducted. Samples from 2 coral species were stripped of their tissues and measured directly. The carbonate remains of other organisms (1 coral, 1 foraminiferan, 1 gastropod, and segments of the calcareous chlorophyte Halimeda sp.) were collected in situ after an undetermined length of exposure of the skeleton to the surrounding water after death of the individual. Readings on these samples were conducted after autoclaving (see above). Subsequently, samples that had some background fluorescence were combusted for $4 \mathrm{~h}$ at $450^{\circ} \mathrm{C}$ to oxidise all organic material, and background measurements were repeated.

Chemical sediment analysis. Chl a analysis was conducted following Sartory \& Grobbelaar (1984). Briefly, ca. $1.5 \mathrm{~g}$ (wet-weight) of frozen sediment was extracted for $5 \mathrm{~min}$ in hot $\left(78^{\circ} \mathrm{C}\right) 95 \%$ ethanol, and subsequently extracted for $24 \mathrm{~h}$ in the dark at ca. $20^{\circ} \mathrm{C}$. After vortexing and centrifugation, $320 \mu \mathrm{l}$ of the extract were used in duplicate measurements on a Synergy HT (Bio-Tek) plate reader at 750 and $665 \mathrm{~nm}$, before and after acidification with $18 \mu \mathrm{l}$ of $0.1 \mathrm{M}$ HCL. After extraction, the sediment was dried for dry weight (DW) determination. An initial comparison of the original spectrophotometer method with this plate reader method showed no statistical difference in the mean value of 28 parallel readings from the same sediments ( $t$-test with df 54, chl a: $t=0.209, \mathrm{p}=0.835$; total pigment: $t=-0.118, \mathrm{p}=0.9063)$. In addition, regression analysis of data obtained from the plate reader against those from the spectrophotometer indicated high agreement between methods $\left(\mathrm{R}^{2}=0.97, \mathrm{n}=28\right)$, both for chl a between ca. 1 and $10 \mu g^{-1}$ DW and total pigment total pigments between 2 and $11 \mathrm{\mu g} \mathrm{g}^{-1} \mathrm{DW}$.

$\mathrm{C}$ and $\mathrm{N}$ were analysed from dried and ground sediment samples. Total $\mathrm{C}$ was analysed on a total carbon analyser (Shimadzu TOC 500). Organic C was analysed on the same instrument after dissolving inorganic $\mathrm{C}$ with $1 \mathrm{M} \mathrm{HCl}$. Total $\mathrm{N}$ in the sediments was analysed on an ANTEK 9000NS analyser. C and N values were calibrated against Acetanilide (Ajax Chemicals) and blanks were run with all samples. In addition, an in-house standard sediment (Gould Island 1.2.C) with similar chemical composition to the samples was run with all batches.

Statistical analyses. Sediment, quantum efficiency and RLC parameters were analysed with mixed model ANOVA. The reefs investigated were regarded as pairs of reefs located in 5 zones as indicated in Fig. 1 (Factor 'Zone', fixed) along the presumed water quality gradient. For sediment parameters, 'Exposure' was regarded as a second fixed factor comparing front reef and back reef locations. Individual 'Reefs' were regarded as random replicates nested in 'Zone'. Analyses for the PAM parameters used a similar design, but the factor 'Exposure' was replaced by the factor 'Method' comparing onboard measurements and in situ readings. PAM readings in situ can be inaccurate because the probe can slightly shift position due to currents or wave action. This may lead to some obvious outliers (e.g. negative or too large efficiency readings), which have to be eliminated before analysis. For these reasons, efficiency readings were averaged over each location and the average used for ANOVAs. Similarly, RLCs were constructed from average readings for each light intensity at each location.

To test for differences among averages in the in situ dark-adaptation experiment, 'Treatment' (with 3 levels: 0 and 15 min adaptation and the surrounding sediments) was treated as a fixed factor and Reef and Location regarded as random and nested factors.

For ANOVAs, quantum efficiency data were arcsine transformed, and all other data were square root transformed. Cochran's $C$-test did not indicate deviations from the assumption of heterogeneity of variances for thus transformed data. Fisher's LSD test was used as a post-hoc test to investigate differences between individual means after ANOVA. Appropriate error terms for each factor were calculated following Underwood (1981).

Correlations between some parameters were described by Pearson's product moment correlation analysis. In addition, I tested the dependence of some parameters on distance from the mainland (read from nautical charts) using regression analysis.

RLCs were fitted using the model of Platt et al. (1980) and light curve parameters as calculated in Kühl et al. (2001). The parameters presented here are the initial slope of the light curve $(\alpha)$, the maximal potential electron transport rate at light saturation $\left(\mathrm{rETR}_{\max }\right)$, the irradiance at onset of light saturation $\left(\mathrm{E}_{\mathrm{k}}\right)$ and the slope beyond the onset of (potential) photoinhibition $(\beta)$. Inclusion of the latter parameter usually improved the curve fit. However, iterations including this parameter 
gave nonsensical results for 4 samples. In those cases, $\beta$ was not included in the model. Curve fitting was conducted using Sigma-Plot (v.7, SPSS); all other statistical analyses were conducted in Statistica (v.6, StatSoft).

\section{RESULTS}

\section{Sediment parameters}

Neither chl a nor total pigments showed statistically significant differences among zones along the presumed nutrient and turbidity gradient, or between back and front reefs (ANOVA; Table 1). Total average chl $a$ values were $1.293 \mu \mathrm{g} \mathrm{g}^{-1} \mathrm{DW}(\mathrm{SE}=0.154)$, and the average total pigment in the uppermost $1 \mathrm{~cm}$ of the sediment was $2.165 \mu \mathrm{g} \mathrm{g}^{-1} \mathrm{DW}(\mathrm{SE}=0.154)$.

Organic $\mathrm{C}$ and $\mathrm{N}$ both exhibited significant differences among zones (ANOVA, Table 1, factor Zone). Post-hoc tests revealed that organic $C$ was significantly elevated in Zones 1 and 2, and that lowest levels were found in Zone 3 (Fig. 2A). Levels in Zones 4 and 5 were somewhat higher again than in Zone 3. Similarly, N values in the sediments decreased from Zones 1 to 3 , with levels in Zones 4 and 5 increasing again (Fig. 2B). The amount of inorganic $\mathrm{C}$ (i.e. mainly $\mathrm{CaCO}_{3}$ ) in the sediments increased significantly with distance from the mainland (regression analysis, $\mathrm{R}^{2}=0.59, F_{1,17}=$ 24.31, p = 0.0001, Fig. 3).

\section{Background fluorescence and quantum efficiency}

Background fluorescence in autoclaved sediments $\left(\mathrm{F}_{0, \text { sed }}\right)$ was measurable in most samples after autoclaving, with values up to 360 units. Background fluorescence followed the same trend as inorganic $C$, with increasing values with distance from the mainland, but the relationship was more pronounced for $\mathrm{F}_{0, \text { sed }}$ (regression analysis, $\left.\mathrm{R}^{2}=0.72, F_{1,17}=44.76, \mathrm{p}<0.0001\right)$. Consequently, these 2 parameters were correlated (correlation analysis, $\mathrm{r}=0.70, \mathrm{p}<0.05, \mathrm{n}=19$ ).

Chemically-pure $\mathrm{CaCO}_{3}$ or $\mathrm{MgCO}_{3}$ did not show any measurable background fluorescence (Table 2). Similarly, coral skeletons freshly stripped of their tissue had no measurable background fluorescence. Carbonate remains from several animal taxa and Halimeda sp. fragments collected on midshelf reefs had varying degrees of background fluorescence, with highest values observed in a sediment sample from an outer shelf reef (Table 2). Combustion at $450^{\circ} \mathrm{C}$ distinctly reduced the background fluorescence.

Table 1. Mixed model ANOVA for pigments, total N and organic C in sediment-biofilms of the Whitsunday area, GBR. Data were square-root transformed for analyses. Values in bold are significant at $\mathrm{p}<0.05$

\begin{tabular}{|c|c|c|c|c|c|c|c|c|c|c|c|c|c|c|}
\hline & \multirow[b]{2}{*}{$\mathrm{df}$} & \multirow[b]{2}{*}{ MS } & \multirow{2}{*}{$\begin{array}{c}\text { Chl a } \\
\quad F\end{array}$} & \multirow[b]{2}{*}{$\mathrm{p}$} & \multicolumn{3}{|c|}{ Total pigment } & \multirow[b]{2}{*}{ df } & \multicolumn{3}{|c|}{ Total N } & \multicolumn{3}{|c|}{ Organic C } \\
\hline & & & & & MS & $F$ & $\mathrm{p}$ & & MS & $F$ & $\mathrm{p}$ & MS & $F$ & $\mathrm{p}$ \\
\hline Zone & 4 & 0.5572 & 0.86 & 0.5466 & 0.0433 & 0.04 & 0.9941 & 4 & $9.4 \times 10^{-5}$ & 17.48 & 0.0038 & 0.0047 & 7.50 & 0.0242 \\
\hline Exposure & 1 & 0.0404 & 0.13 & 0.7378 & 0.2392 & 1.01 & 0.3612 & 1 & $<0.1 \times 10^{-5}$ & - & - & 0.0005 & 0.07 & 0.8083 \\
\hline $\operatorname{Reef}(\mathrm{Z})$ & 5 & 0.6500 & $18.30<$ & $<0.0001$ & 0.8950 & 10.29 & $<0.0001$ & 5 & $0.5 \times 10^{-5}$ & 0.84 & 0.5371 & 0.0006 & 0.57 & 0.7184 \\
\hline $\mathrm{Z} \times \mathrm{E}$ & 4 & 0.2043 & 0.63 & 0.6605 & 0.5107 & 2.15 & 0.2110 & 4 & $7.9 \times 10^{-5}$ & 0.78 & 0.5838 & 0.0027 & 0.38 & 0.8160 \\
\hline $\mathrm{E} \times \mathrm{R}(\mathrm{Z})$ & 5 & 0.3226 & $9.08<$ & $<0.0001$ & 0.2370 & 2.72 & 0.0276 & 5 & $10.1 \times 10^{-5}$ & 15.67 & $<0.0003$ & 0.0070 & 6.39 & 0.0011 \\
\hline Residual & 60 & 0.0355 & & & 0.0869 & & & 20 & $0.6 \times 10^{-5}$ & 0.001 & & & & \\
\hline
\end{tabular}
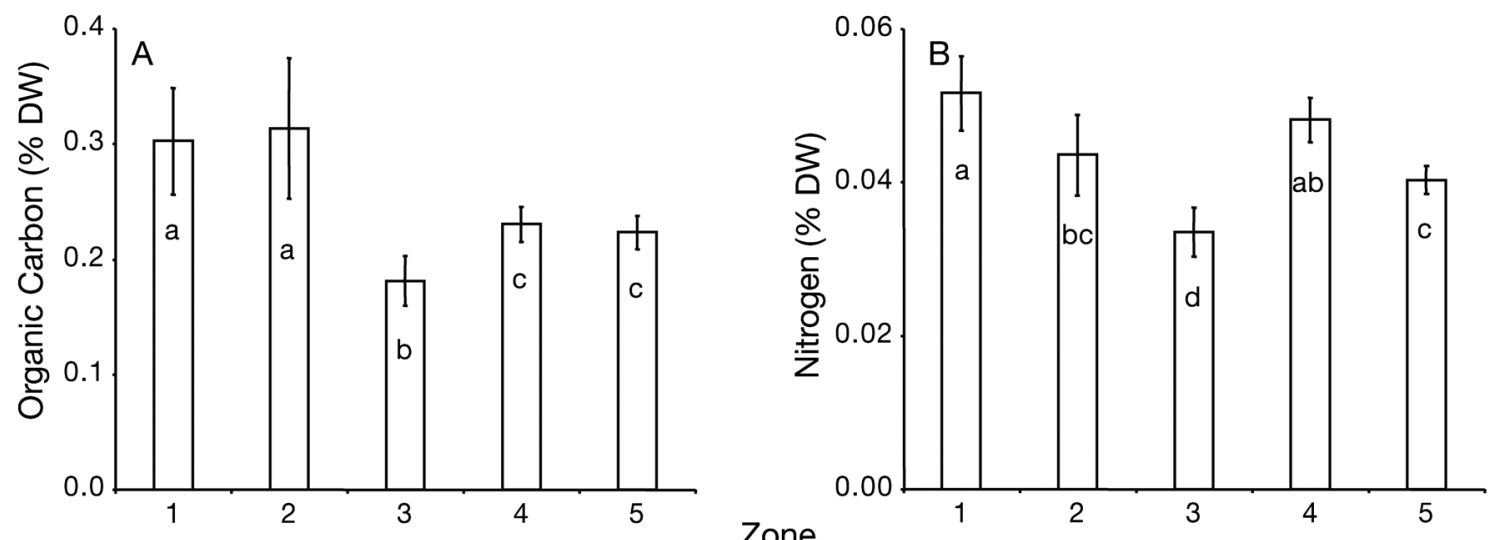

Fig. 2. (A) Organic $\mathrm{C}$ and (B) $\mathrm{N}$ values in sediments from 5 zones in the Whitsunday area of the GBR. Error bars $=1 \mathrm{SE}, \mathrm{N}=4$. Averages sharing the same letter were not significantly different $(p>0.05)$ in the post-hoc comparison 


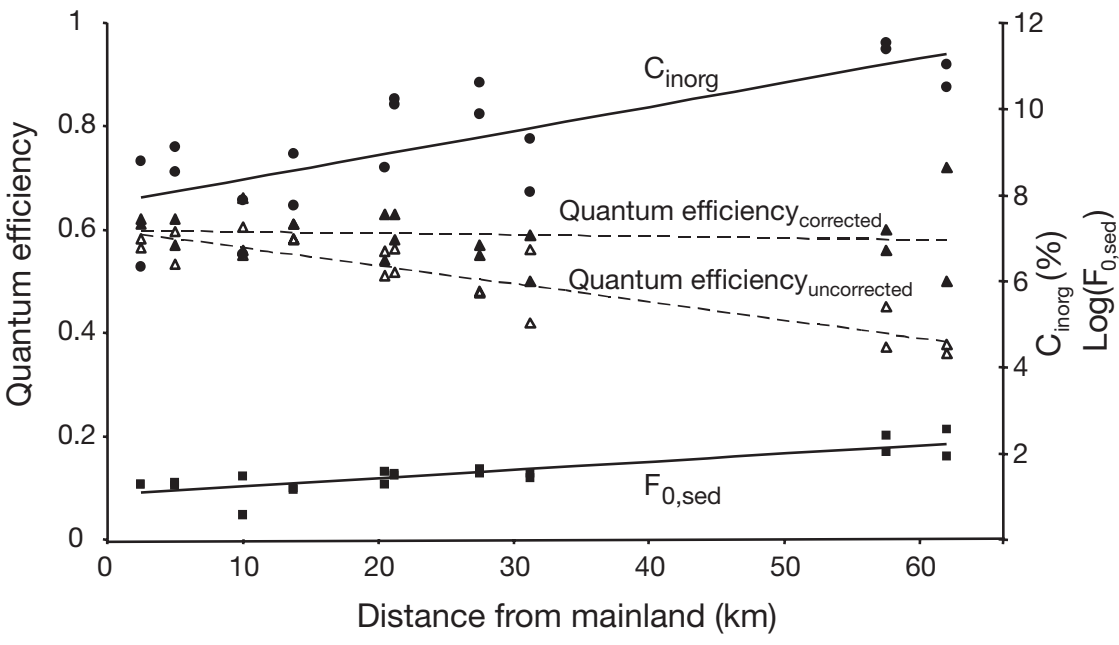

Fig. 3. Regression plot of inorganic $\mathrm{C}\left(\mathrm{C}_{\text {inorg }}\right)$ and background fluorescence $\left(\mathrm{F}_{0, \text { sed }}\right)$ as a function of distance from the mainland. Quantum efficiency (average of $\mathrm{F}_{\mathrm{v}} / \mathrm{F}_{\mathrm{m}}$ and $\phi_{\mathrm{PSII}}$ ) is given uncorrected (Quantum efficiency uncorrected) and corrected (Quantum efficiency ${ }_{\text {corrected}}$ ) for $\mathrm{F}_{0, \text { sed }}$

Quantum efficiency (averaged over effective and maximum quantum efficiency of PSII, see below) values not corrected for this background fluorescence exhibited an opposite trend to $\mathrm{CaCO}_{3}$ and background fluorescence, with an apparent decline of quantum efficiency towards outer shelf reefs (regression analysis, $\mathrm{R}^{2}=0.79, F_{1,17}=64.19, \mathrm{p}<0.0001$, Fig. 3). In contrast, once efficiency estimates were corrected for background fluorescence, there was no decline with distance from the mainland apparent (regression analysis, $\mathrm{R}^{2}=0.01, F_{1,17}=0.21, \mathrm{p}=0.6500$ ). All subsequent fluorescence or quantum efficiency values given were corrected for $\mathrm{F}_{0, \text { sed }}$.

Differences in average minimum fluorescence were statistically significant between in situ (F) and laboratory dark-adapted $\left(\mathrm{F}_{0}\right)$ treatments and between the zones (Table 3, factors Method and Zone); furthermore, the interaction term between these 2 main factors was significant. However, graphical inspection of this interaction term showed that trends were consistent over the different zones (Fig. 4A). F for Zones 1 to 4 were on average 3.7 times higher than estimates of $F_{0}$. The interaction term was significant because the differences in Zone 5 were less pronounced. F estimates decreased towards Zone 4 and were higher again in Zone 5 (Fig. 4). Neither $F_{0}$ nor $F$ were significantly correlated with chl a content of the upper $1 \mathrm{~cm}$ of the sediments ( $\mathrm{F}: \mathrm{r}=-0.012, \mathrm{p}=0.962 ; \mathrm{n}=19 ; \mathrm{F}_{0}: \mathrm{r}=$ $0.3032, p=0.194, \mathrm{n}=20$ ). The effective quantum efficiency $\left(\phi_{\text {PSII,corr }}\right.$ overall average $\left.0.59, \mathrm{SE}=0.02\right)$ was not significantly different (Table 3, ANOVA factor Method) from the maximum quantum efficiency measured in the laboratory $\left(\mathrm{F}_{\mathrm{v}} / \mathrm{F}_{\mathrm{m}, \text { corr }}\right.$ overall average 0.56 ,
$\mathrm{SE}=0.01)$. The quantum efficiency of PSII (averaged $\phi_{\text {PSII,corr }}$ and $F_{\mathrm{v}} / \mathrm{F}_{\mathrm{m}, \text { corr }}$ ) showed no significant differences between zones (Fig. 4B, Table 3, ANOVA factor Zones), confirming regression results discussed above (see Fig. 3).

Statistical analyses of in situ darkadaptation experiments indicated significant differences among treatments (Table 4, factor Treatment). Post-hoc analyses revealed that average fluorescence 15 min after darkadaptation $\left(\mathrm{F}_{0}, 39.9\right.$ arbitrary units) was significantly lower compared to $\mathrm{F}$ at the beginning of the experiment (Fisher's LSD-test, $\mathrm{p}=0.0179,107.1$ arbitrary units) and $F$ in the surrounding sediments (Fisher's LSDtest, $\mathrm{p}=0.0115,117.3$ arbitrary units). The latter 2 treatments did not differ significantly (Fisher's LSD-test, $\mathrm{p}=0.6035$ ). Thus, $\mathrm{F}_{0}$ values after 15 min dark-adaptation decreased to nearly one-third of their original values. Some significant differences in $\mathrm{F}_{0}$ also existed among locations (Table 4, factor Locations). However, averages were consistently lower at each of the 8 sites after 15 min dark-adaptation when compared to initial values and surrounding sediment (data not shown).

Table 2. Background fluorescence of calcium and magnesium carbonates, and a variety of calcareous reef organisms after autoclaving for $2 \mathrm{~h}$ and subsequent combustion at $450^{\circ} \mathrm{C}$ for $4 \mathrm{~h}$. Averages of 6 readings given in arbitrary fluorescence units (SD in brackets)

\begin{tabular}{|c|c|c|}
\hline & $\begin{array}{c}\text { After } \\
\text { autoclaving }\end{array}$ & $\begin{array}{c}\text { After } \\
\text { combustion }\end{array}$ \\
\hline $\mathrm{CaCO}_{3}$ & $1.0(2.2)$ & - \\
\hline $\mathrm{MgCO}_{3}$ & $0.0(0.0)$ & - \\
\hline $\begin{array}{l}\text { Acropora sp. }{ }^{\mathrm{a}} \\
\text { (fresh skeleton) }\end{array}$ & $0.0(0.0)$ & - \\
\hline $\begin{array}{l}\text { Acropora sp. }^{\mathrm{a}} \\
\text { (aged skeleton) }\end{array}$ & $78.2(9.5)$ & $18.5(8.1)$ \\
\hline $\begin{array}{l}\text { Pocillopora damicornis }{ }^{\mathrm{a}} \\
\text { (fresh skeleton) }\end{array}$ & $0.0(0.0)$ & - \\
\hline Trochus sp. ${ }^{\mathrm{b}}$ & $50.8(26.2)$ & $8.8(7.2)$ \\
\hline Marginopora vertebralis ${ }^{\mathrm{c}}$ & $30.2(8.1)$ & $16.7(9.7)$ \\
\hline Halimeda sp. ${ }^{\mathrm{d}}$ segments & $80.8(32.7)$ & $23.0(8.1)$ \\
\hline $\begin{array}{l}\text { Dip Reef sediment } \\
\text { (outer shelf) }\end{array}$ & $183.1(20.2)$ & $55.2(13.9)$ \\
\hline
\end{tabular}


Table 3. Mixed model ANOVA for minimum fluorescence $\left(\mathrm{F}_{0}\right.$ and $\mathrm{F}_{\text {, corrected }}$ for $\left.\mathrm{F}_{0, \text { sed }}\right)$ and quantum efficiency $\left(\mathrm{F}_{\mathrm{v}} / \mathrm{F}_{\mathrm{m} \text {,corr }}\right.$ and $\left.\phi_{\text {PSII,corr }}\right)$ in sediment-biofilms of the Whitsunday area, GBR. $\mathrm{F}_{0}$ and $\mathrm{F}$ data were square-root transformed and efficiency data were arcsine transformed for analyses. Values in bold are significant at $\mathrm{p}<0.05$

\begin{tabular}{|lrrrrrrrr|}
\hline & & \multicolumn{3}{c}{$\mathrm{F}_{0,} \mathrm{~F}$} & \multicolumn{3}{c|}{$\mathrm{F}_{\mathrm{v}} / \mathrm{F}_{\mathrm{m}, \text { corr }}, \phi_{\mathrm{PSI}, \text { corr }}$} \\
& df & $\mathrm{MS}$ & $\mathrm{F}$ & $\mathrm{p}$ & $\mathrm{MS}$ & $F$ & $\mathrm{p}$ \\
\hline Zone & 4 & 30.9067 & 6.87 & $\mathbf{0 . 0 2 9 3}$ & 0.0238 & 3.60 & $\mathbf{0 . 0 9 6 1}$ \\
Method & 1 & 263.7323 & 324.48 & $\mathbf{< . 0 0 0 1}$ & 0.0085 & 1.30 & 0.3060 \\
Reef(Z) & 5 & 4.5276 & 1.91 & 0.1378 & 0.0066 & 0.79 & 0.5705 \\
$\mathrm{Z} \times \mathrm{M}$ & 4 & 5.3463 & 6.58 & $\mathbf{0 . 0 3 1 6}$ & 0.0182 & 2.77 & 0.1470 \\
$\mathrm{M} \times \mathrm{R}(\mathrm{Z})$ & 5 & 0.8128 & 0.34 & 0.8808 & 0.0066 & 0.78 & 0.5729 \\
Residual & 20 & 2.3719 & & 0.0084 & & & \\
& & & & & & & \\
\hline
\end{tabular}

compensation point clearly increased towards the outer shelf reef (Fig. 4C); post-hoc tests revealed that values from Zone 5 were significantly higher than in Zones 1, 2 and 4 (Fisher's LSDtest, $\mathrm{p}<0.05$ ).

Fig. 4C also depicts average PAR readings for each zone in situ (measured at the depth and time of the PAM readings). These values nearly triple from the inner reefs (Zone 1) towards the midshelf reefs (Zone 5). Correlation analysis using averages from each location confirmed that $\mathrm{E}_{\mathrm{k}}$ values obtained from RLC measure-
Table 4. Nested ANOVA of fluorescence (in arbitrary units, corrected for $\mathrm{F}_{0, \text { sed }}$ ) of in situ samples after $0(\mathrm{~F})$ and $15 \mathrm{~min}$ of dark-adaptation $\left(\mathrm{F}_{0}\right)$, and surrounding sediments $(\mathrm{F})$. Data were square root transformed for analyses. Values in bold are significant at $\mathrm{p}<0.05$

\begin{tabular}{|lrrrr|}
\hline & df & MS & \multicolumn{1}{c|}{$F$} & \multicolumn{1}{c|}{ p } \\
\hline Treatment & 2 & 863.95 & 11.55 & $\mathbf{0 . 0 0 8 8}$ \\
Reef (T) & 4 & 74.80 & 0.22 & 0.9942 \\
Location (R) & 6 & 331.92 & 50.85 & $<\mathbf{0 . 0 0 0 1}$ \\
Residual & 345 & 6.53 & & \\
\hline
\end{tabular}

\section{Rapid light curves (RLCs)}

The model chosen gave a good fit to the RLCs, with somewhat better fit for in situ measurements (overall average $\mathrm{R}^{2}=0.986, \mathrm{SE}=0.003, \mathrm{n}=20$ ) than for measurements in the laboratory $\left(\mathrm{R}^{2}=0.859, \mathrm{SE}=0.021, \mathrm{n}=\right.$ 20). This was likely to be caused by the lower fluorescent signal in the latter samples (see above) resulting in lower signal to noise ratios.

The initial slope of the light curves $(\alpha)$ showed significant differences (ANOVA, factor Method, Table 5) between in situ measurements (average $=0.664, \mathrm{SE}=$ 0.023 ) and onboard readings (average $=0.418, \mathrm{SE}=$ 0.032). Similarly, the maximal potential electron transport rate at light saturation $\left(\mathrm{rETR}_{\max }\right)$ was significantly higher (ANOVA, factor Method, Table 5) during in situ readings $(63.60, \mathrm{SE}=3.80)$ than in the laboratory $(20.54, \mathrm{SE}=2.72)$. No differences between the zones were detected for $\alpha$ or $\mathrm{rETR}_{\max }$ (ANOVA, factor Zone, Table 4).

The light intensity at onset of saturation $\left(\mathrm{E}_{\mathrm{k}}\right)$ was significantly higher (ANOVA, factor Method, Table 5) for in situ measurements (average $=96.76, \mathrm{SE}=5.48$ ) compared to values obtained in the laboratory under low light conditions (average $=57.41, \mathrm{SE}=8.95$ ). Average $E_{k}$ values were also significantly different among zones (ANOVA, factor Zone, Table 5). The light

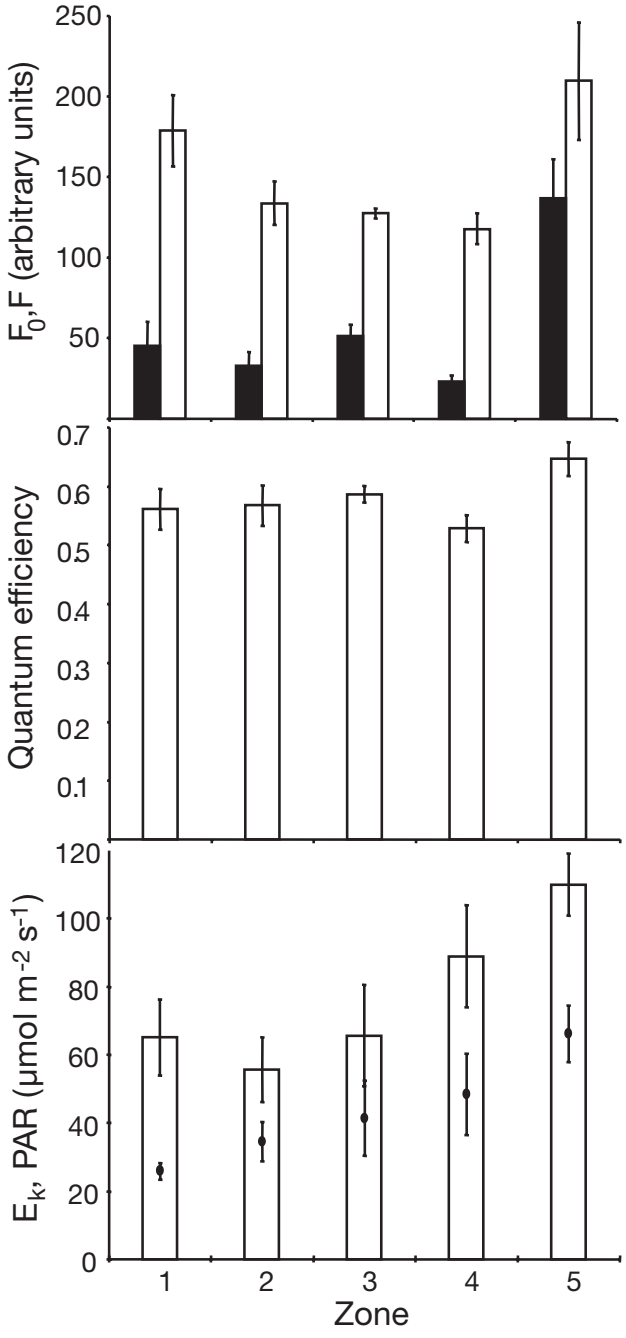

Fig. 4. (A) Minimum fluorescence $\left(F_{0}\right.$ : black bars; F: white bars), (B) quantum efficiency (average of $F_{v} / F_{m}$,corr and $\left.\phi_{\text {PSII,corr }}\right)$ and $(\mathrm{C})$ light saturation point $\left(\mathrm{E}_{\mathrm{k}}\right.$ : white bars) and incident light (PAR: black dots) values in biofilm communities from 5 zones in the Whitsunday area of the GBR. Error bars = $1 \mathrm{SE}, \mathrm{N}=4$ 
Table 5. Mixed model ANOVA for RLC parameters (initial slope $\alpha$, asymptotic maximum relative electron transport rate $\mathrm{rETR}_{\max }$ and light compensation point $\mathrm{E}_{\mathrm{k}}$ ) in sediment-biofilms of the Whitsunday area, GBR. Data were square-root transformed for analyses. Values in bold are significant at $p<0.05$

\begin{tabular}{|c|c|c|c|c|c|c|c|c|c|c|}
\hline & df & MS & $\begin{array}{l}\alpha \\
F\end{array}$ & $\mathrm{p}$ & MS & $\begin{array}{c}\mathrm{rETR}_{\max } \\
F\end{array}$ & $\mathrm{p}$ & MS & $\begin{array}{c}\mathrm{E}_{\mathrm{k}} \\
F\end{array}$ & $\mathrm{p}$ \\
\hline Zone & 4 & 0.00205 & 1.54 & 0.3206 & 3.512 & 2.47 & 0.1735 & 13.5931 & 5.52 & 0.0445 \\
\hline Method & 1 & 0.05991 & 18.99 & 0.0073 & 118.151 & 181.32 & $<0.0001$ & 67.3622 & 14.54 & 0.0125 \\
\hline Reef(Z) & 5 & 0.00133 & 1.12 & 0.3815 & 1.418 & 1.69 & 0.1830 & 2.4619 & 1.15 & 0.3674 \\
\hline $\mathrm{Z} \times \mathrm{M}$ & 4 & 0.00102 & 0.32 & 0.8519 & 1.371 & 2.12 & 0.2178 & 5.4739 & 1.18 & 0.4197 \\
\hline $\mathrm{M} \times \mathrm{R}(\mathrm{Z})$ & 5 & 0.00315 & 2.65 & 0.0540 & 0.652 & 0.78 & 0.5765 & 4.6329 & 2.17 & 0.0981 \\
\hline Residual & 20 & 0.00119 & & & 0.837 & & 2.1320 & & & \\
\hline
\end{tabular}

ments both in situ $(\mathrm{r}=0.62, \mathrm{p}<0.05, \mathrm{n}=17)$ and in the laboratory $(\mathrm{r}=0.58, \mathrm{p}<0.05, \mathrm{n}=18)$ were significantly correlated with ambient average PAR readings. Similarly, $\mathrm{rETR}_{\max }$ values were correlated with incident PAR values for both in situ measurements $(\mathrm{r}=0.49, \mathrm{p}<$ $0.05, \mathrm{n}=17)$ and laboratory readings $(\mathrm{r}=0.58, \mathrm{p}<0.05$, $\mathrm{n}=18$ ). No significant correlations existed between $\alpha$ and PAR (in situ: $\mathrm{r}=-0.17, \mathrm{p}>0.05, \mathrm{n}=17$; laboratory: $\mathrm{r}=-0.26, \mathrm{p}>0.05, \mathrm{n}=18$ ).

No formal statistical analysis was conducted on the $\beta$ values, because removal of that term from some of the light curves lead to an unbalanced statistical design. However, values were relatively low, with very low values observed in Zones $1(0.010, \mathrm{SE}=0.006, \mathrm{n}=5)$ and $5(0.016, \mathrm{SE}=0.004, \mathrm{n}=8)$, and intermediate values in Zones $2(0.036, \mathrm{SE}=0.018, \mathrm{n}=8), 3(0.068, \mathrm{SE}=$ $0.026, \mathrm{n}=8)$, and $4(0.114, \mathrm{SE}=0.042, \mathrm{n}=6)$.

\section{DISCUSSION}

\section{Water and sediment quality}

The main purpose of this paper was to investigate the use of PAM fluorometry as an indicator for nutrient and light status of biofilms on coral reef sediments along a water quality gradient. This gradient of water column chl a as a proxy for phytoplankton biomass was described in a long-term chlorophyll monitoring study (Brodie et al. in press). In the present study, $\mathrm{N}$ and organic $\mathrm{C}$ values in the sediments confirmed - at least for the inner 3 zones - that values decrease along the presumed gradient. These inner 3 zones were similar to the ones previously investigated by van Woesik et al. (1999). These authors observed a similar decrease in $\mathrm{N}$ and organic $\mathrm{C}$ in the sediments with increasing distance from the $\mathrm{O}^{\prime} \mathrm{Connell}$ and Proserpine rivers (Fig. 1), and suggested that recent changes in water quality along this gradient lead to distinct community changes on the coral reefs. Although only snapshot measurements, light data presented here and water column chlorophyll and secchi disk readings conducted during the same trip (K. Fabricius unpubl. data) support the existence of this gradient.

Patterns for sediment parameters were slightly less distinct for Zone 4 and the mid shelf reefs (Zone 5), with both $\mathrm{N}$ and organic $\mathrm{C}$ values in the sediments slightly increasing again. It may be that at larger distances from the coast the land-based nutrient input becomes less important to sediment parameters, and that other sources of nutrient are more prevalent. One of these sources can be upwelling of nutrient-rich deeper water on the outer shelf reefs, which can periodically reach outer shelf and midshelf reefs (Andrews \& Gentien 1982).

Some differences in $\mathrm{N}$ and organic $\mathrm{C}$ values in the different zones may also be attributed to different geochemical processes in terrigeneous and carbonate sediments. However, although a distinct increase in carbonate was observed towards the outer shelf, sediments on the reefs in the inner zones still had inorganic $\mathrm{C}$ values equivalent to more than $62 \%$ $\mathrm{CaCO}_{3}$. The increase of inorganic $\mathrm{C}$ with distance from the shoreline is well described in other areas of the GBR (e.g. Hamilton 2001, Brunskill et al. 2002). This increase reflects decreasing importance of terrigeneous (siliceous) sediment. Sediments of outer shelf reefs are nearly entirely composed of the remains of calcareous organisms, mainly foraminifera, corals and the green alga Halimeda sp. (Scoffin \& Tudhope 1985).

\section{Background fluorescence, quantum efficiency and minimum fluorescence}

Background fluorescence $\left(\mathrm{F}_{0, \text { sed }}\right)$ was high in many samples, and distinctly increased towards the zones more distant from the mainland. Thus, uncorrected quantum efficiency estimates mimicked lower efficiency (and higher biomass as indicated by $\mathrm{F}_{0}$ or $\mathrm{F}$ ) in 
zones of lower nutrient availability. The increase in $\mathrm{F}_{0 \text {,sed }}$ correlated with an increase in $\mathrm{CaCO}_{3}$. However, chemically-pure carbonate and fresh coral skeleton did not have any fluorescence, suggesting that an unknown fluorescent substance accumulates in the skeleton of calcareous organisms to a greater extent with increasing distance from the mainland. The fact that fluorescence was reduced upon combustion suggests that this substance may be of organic origin. A possible source could be humic acids such as tannins and lignins.

There was no significant difference between maximum quantum efficiency $\left(\mathrm{F}_{\mathrm{v}} / \mathrm{F}_{\mathrm{m}, \mathrm{corr}}\right)$ measurements obtained in the laboratory and in situ measurements of effective quantum efficiency of PSII ( $\left.\phi_{\text {PSII,corr }}\right)$. Theoretically, dark-adapted samples are expected to obtain higher values because PSII reaction centres are fully open. Samples measured in situ were measured outside the highest light period between 10:30 and 13:30 h, and at a depth between 6 and $8 \mathrm{~m}$. Therefore, in situ light values were only in the range of 20 and $90 \mu \mathrm{mol}$ photon $\mathrm{m}^{-2} \mathrm{~s}^{-1}$. However, at light intensities over $100 \mu \mathrm{mol}$ photon $\mathrm{m}^{-2} \mathrm{~s}^{-1}$ in shallow depth (2 to $5 \mathrm{~m}$, data not shown) distinctly lower PSII effective quantum efficiency values (below 0.5) were observed. Effective quantum efficiency is negatively correlated with the amount of incident light (Serôdio 2003), as was also observed during RLC measurements in the present study (data not shown). It appears that under light conditions in situ as chosen in this study (which were all distinctly below $E_{k}$ values, see below) most reaction centres are still open, and that the difference is not measurable or small enough to be outweighed by potential negative impacts through disturbance of the sediments for laboratory measurements.

In contrast to the quantum efficiency, the minimum fluorescence measured under steady-state light conditions in situ (F) was much higher compared to darkadapted measurements in the laboratory $\left(\mathrm{F}_{0}\right)$. These parameters can be used as proxies for algal biomass involved in photosynthesis under a variety of temperature and light conditions (Serôdio et al. 2001). In the present study, in vitro measurements were conducted by integrating the uppermost $1 \mathrm{~cm}$ sediment. Therefore, enhanced biomass measured in situ is most likely caused by a concentration of biomass on the surface. In the first 4 zones along the gradient, F estimates indicated a decrease in biomass concentrated on the sediment surface, but the total biomass in the uppermost $1 \mathrm{~cm}$ of sediment (estimated as either $\mathrm{F}_{0}$ after mixing in the laboratory or as chl a values) showed no such trend. The difference between field and laboratory readings is smaller and not significant for the midshelf reefs. These reefs have much coarser sediments (author's unpubl. data) and these data confirm previ- ous observations (see below) that benthic microalgae penetrate much deeper into these highly mobile sediments.

The 15 min dark-adaptation also reduced $F_{0}$ estimates during in situ experiments. Thus, the reduction in $\mathrm{F}_{0}$ observed in vitro may also be caused by reduced biomass on the surface during dark periods. Consalvey et al. (2004) also observed decreases of $F_{0}$ after darkadaptation in situ, and interpreted this as a sign of vertical migration of the algae into the sediment when in the dark. Changes in $\mathrm{F}_{0}$ on the surface of the sediment over time were also related to vertical migration in several other studies (Perkins et al. 2001, Serôdio et al. 2001). Because nutrient concentrations in the pore water of coral reefs are often an order of magnitude higher than in the water column (e.g. Schaffelke et al. 2004), it is possible that microalgae migrate into the sediment to take up nutrients from the interstitial water during periods of insufficient light for photosynthesis.

No relationship was detected between $F_{0}$ and $F$ and the chlorophyll values measured after extraction. In contrast, Barranguet \& Kromkamp (2000) and Serôdio (2004) previously described a good relationship between $\mathrm{F}_{0}$ and microphytobenthos biomass. Similar to $\mathrm{F}_{0}$ readings, chl a measurements presented here were integrated over the uppermost $1 \mathrm{~cm}$. The absence of a correlation between chl $a$ and $F_{0}$ may be taken as additional evidence that the latter readings do not represent the average of the uppermost $1 \mathrm{~cm}$, but is additionally biased through vertical migration during dark periods. Barranguet \& Kromkamp (2000) extracted chlorophyll from only the first mm of sediment, and a good relationship between $\mathrm{F}_{0}$ and microphytobenthos biomass was observed. I opted to measure over the first $\mathrm{cm}$ because (1) midshelf sediments are very coarse and slicing cores to much less then $1 \mathrm{~cm}$ is not possible, and (2) initial tests with both PAM fluorometry and ethanol extraction (author's unpubl. data) had indicated the presence of chlorophyll at more than $10 \mathrm{~cm}$ depth in midshelf reef sediments. The lower concentration factor on the surface of midshelf sediment was confirmed by measurements of $F_{0}$ and $F$ (see above). However, the question why midshelf reef sediment did not show higher chlorophyll values than the inshore reefs (as would be expected by highest $F_{0}$ and $F$ averages) remains unresolved.

Average maximum and effective quantum efficiency of PSII measured here was close to 0.6. This is somewhat below values found in higher plants (Kromkamp et al. 1998), but well within the range of physiologically healthy and nutrient sufficient planktonic (e.g. Geider et al. 1993) and benthic microalgae (e.g. Kromkamp et al. 1998, Hartig et al. 1998, Underwood 2002, Serôdio et al. 2005). 
In phytoplankton samples, nutrient limitation often leads to decreased efficiency of PSII. For example, Nstarved cultures of the diatom Phaeodactylum tricornutum distinctly decreased from values of around 0.6 to less then 0.2 after several days, with a similar but less pronounced trend for P starvation (Geider et al. 1993). Both effective and maximum efficiency of PSII were distinctly reduced under N, P or Si starvation in 2 planktonic diatom species studied by Lippemeier et al. (2001). Several other plankton species of the Chlorophyta and Bacillariophyta also showed a clear decrease in efficiency with P limitation (Graziano et al. 1996, Beardall et al. 2001). In most of these studies, the efficiency of PSII increased soon after re-supply of the limiting nutrient. Generally, in these experiments, algae were kept in batch cultures under actual nutrient starvation conditions. Reductions in PSII efficiency under nutrient starvation were usually related to a decrease in the ratio of functional over non-functional (i.e. centres without or with damaged D1 protein) PSII centres (Lippemeier et al. 2001). It is likely that nutrient starvation represents a more severe stress for the photosystem than nutrient limitation.

One of the main hypotheses for the present study was that coral reef microalgae are nutrient limited and, therefore, one should find changes in quantum efficiency along a presumed gradient from high to lower nutrient availability. This assumption was based on a variety of experimental studies that all found distinct productivity enhancement of tropical marine microphytobenthos under nutrient (especially N) addition. Uthicke \& Klumpp (1997, 1998) and Uthicke (2001) demonstrated production enhancement in situ and in aquaria within $12 \mathrm{~h}$, and biomass enhancement after several days of ammonium enhancement (either added directly or as an excretion product from benthic invertebrates) of only 1 to $2 \mu \mathrm{M}$ above background level. Similarly, several other studies (Dizon \& Yap 2003, Heil et al. 2004, Gottschalk 2005) demonstrated rapid production enhancement or biomass increases of coral reef microphytobenthos upon $\mathrm{N}$ addition, for both inshore sediments similar in carbonate content to the inner zones investigated here and also for sediments with carbonate content as high as on midshelf reefs.

Therefore, it was surprising that no changes in quantum efficiency were detected in the present study. In aquarium experiments, Gottschalk (2005) found a significant increase in microphytobenthos biomass after $7 \mathrm{~d}$ of $\mathrm{N}$ addition, but also observed no changes in maximum quantum efficiency. Thus, quantum efficiency measurements have some limitations when used to infer nutrient limitation in microphytobenthos communities. Firstly, it is difficult to determine the penetration depth of the measurement light into the sediment, but errors introduced by integrating over several depths are relatively small (Forster \& Kromkamp 2004). Secondly, the exact biomass involved in the production is difficult to determine because benthic microalgae on coral reefs are mainly composed of pennate diatoms (Underwood 2002, Gottschalk 2005). These algae are highly mobile and conduct vertical migration depending on tide levels, time of the day or changes in light levels (Perkins et al. 2002). Induced by higher nutrient levels, differential vertical migration may alter the taxonomic composition on the top layer of the sediment towards more productive species with higher nutrient demand. Thus, the actual community involved in photosynthesis under a specific nutrient regime at a specific time may not be nutrient limited, but additional $\mathrm{N}$ can enhance community productivity because more productive species become dominant on the sediment surface. Testing this hypothesis requires investigation of the actual species distribution under different nutrient regimes, for example in thinly sliced sediment cores.

\section{Rapid light curves (RLCs)}

All light curve parameters statistically analysed (the initial slope $\alpha$, the asymptotic maximum relative electron transport rate rETR $_{\max }$, and the light compensation point $E_{k}$ ) were significantly lower when measured at low light conditions in the laboratory when compared to in situ readings. Although these parameters may also be influenced by mixing of the uppermost $\mathrm{cm}$ of sediment (e.g. by bringing relatively more low lightadapted cells to the surface), it may be assumed that some photo-physiological changes have also occurred as an adaptation to lower light levels prior to measurements in the laboratory. Rapid changes in $P-E$ curves of microphytobenthos have been described using oxygen respirometry (Uthicke \& Klumpp 1998).

$\mathrm{E}_{\mathrm{k}}$ values measured on intertidal sediments (Kromkamp et al. 1998, Barranguet \& Kromkamp 2000) were much higher than measured in the present study, probably because they were subjected to much higher light levels than the subtidal ( 6 to $8 \mathrm{~m}$ ) communities investigated here. rETR $_{\max }$ values were also found to be somewhat higher on intertidal sediments (differences in the formulae used by several authors are taken into consideration in the discussion below) (Kromkamp et al. 1998, Barranguet \& Kromkamp 2000). $E_{k}$ and rETR $_{\max }$ values on subtidal calcareous sediments in Fiji are more comparable to values measured in this study (Underwood 2002). These figures indicate that microphytobenthos communities are highly adaptable and that RLC curve parameters reflect in situ irradiance. Light availability clearly increased along the presumed water quality gradient in the present study. $\mathrm{E}_{\mathrm{k}}$ values 
exhibited a similar increase, and always remained above the incident light levels. Serôdio et al. (2005) also demonstrated that $\mathrm{E}_{\mathrm{k}}$ was highly correlated with incident irradiance in microphytobenthos. In addition to potentially rapid changes in the photophysiology of individual cells, these may also regulate the amount of light adsorbed through vertical migration along the light gradient into the sediment (Serôdio et al. 2001). However, photophysiological changes are not necessarily instantaneously, as illustrated by the fact that $E_{k}$ values measured on board ship (which were conducted 1 to $2 \mathrm{~h}$ after removal from in situ conditions) were still clearly elevated in Zones 4 and 5 when compared to those from the inner zones.

Similarly, $\mathrm{E}_{\mathrm{k}}$ and $\mathrm{rETR}_{\max }$ were both correlated with in situ light levels, even when measured onboard after adaptation to lower light levels. Although changes in light curve parameters were demonstrated, these changes were not sufficient to fully compensate for reduced light conditions due to increased turbidity. This can be illustrated by comparing production at average incident light levels during the in situ readings, calculated using the light intensity and RLC parameters measured in each respective zone. The relative electron transport rate (rETR) at that intensity increased from values of ca. 16 to 20 in Zones 1 and 2, respectively, to values of 26 to 32 in the clearer water of Zones 4 and 5. Thus, there are clear indications that productivity of biofilms is limited by light availability in zones with enhanced turbidity.

\section{CONCLUSIONS}

This study highlighted that in situ PAM fluorometry provides a valuable tool with which to investigate photophysiology of benthic microphytobenthos on calcareous sediments. Fluorescence and RLC parameters indicated that measurements in situ are preferable and more reflective of natural situations compared to cores or integration over the upper sediment layers. This study also demonstrated that care needs to be taken when sediment communities are measured, as illustrated by the misleading results when background fluorescence is not taken into consideration. Similarly, dark-adapted readings both in situ and in vitro represent estimates of only a subset of the community involved in photosynthesis when light is available. RLC parameters, especially changes in $E_{k}$ along a gradient of light availability, indicated that photosynthesis in these communities is highly adaptable. Whether adaptations reflect cellphysiological changes or alterations in community composition through vertical migration requires further investigation. Similarly, the hypothesis that pro- ductivity of these communities increases under higher nutrient regimes, due to vertical migration of opportunistic species with higher nutrient demand to the photic zone of the sediment, requires testing in future investigations.

Acknowledgements. I am indebted to K. Fabricius and D. Alongi, who provided very valuable comments on an earlier draft of the manuscript. I am also very grateful for the comments of 3 anonymous reviewers, which greatly improved the manuscript. I thank the crew of the RV 'Lady Basten' for their assistance during the field work of this project.

\section{LITERATURE CITED}

Alongi DM, McKinnon AD (2005) The cycling and fate of terrestrially derived sediments and nutrients in the coastal zone of the Great Barrier Reef shelf. Mar Pollut Bull 51: $239-252$

Andrews JC, Gentien P (1982) Upwelling as a source of nutrients for the Great Barrier Reef ecosystem: a solution to Darwin's question? Mar Ecol Prog Ser 8:257-269

Barranguet C, Kromkamp J (2000) Estimating primary production rates from photosynthetic electron transport in estuarine microphytobenthos. Mar Ecol Prog Ser 204: $39-52$

Beardall J, Roberts S, Young E (2001) Approaches for determining phytoplankton nutrient limitation. Aquat Sci 63: $44-69$

Brodie J, De'ath G, Waterhouse J, Furnas M, Bainbridge Z, Devlin $M$, Haynes $M$, Wright $M$ (in press) Long-term chlorophyll monitoring in the Great Barrier Reef lagoon: status report no. 2, 1993-2005. Research Report No. 05/06. Australian Centre for Tropical Freshwater Research, Townsville

Brunskill G, Zagorskis I, Pfitzner J (2002) Carbon burial rates in sediments and a carbon mass balance for the Herbert River region of the Great Barrier Reef continental shelf, north Queensland, Australia. Estuar Coast Shelf Sci 54: $677-700$

Consalvy M, Jesus B, Perkins R, Brotas V, Underwood G, Paterson D (2004) Monitoring migration and measuring biomass in the benthic biofilms: the effects of dark/far-red adaptation and vertical migration on fluorescence measurements. Photosynth Res 81:91-101

Dizon RM, Yap HT (2003) Metabolic changes and compositional shifts in nutrient-enriched tropical reef sediment communities. Sci Mar 67:117-127

Fabricius KE (2005) Effects of terrestrial runoff on the ecology of corals and coral reefs: review and synthesis. Mar Pollut Bull 50:125-146

Fabricius KE, De'ath G, McCook L, Turak E, Williams DM (2005) Changes in algal, coral and fish assemblages along water quality gradients on the inshore Great Barrier Reef. Mar Pollut Bull 51:384-398

Falkowski P, Raven J (1997) Aquatic photosynthesis. Blackwell Science, Melbourne

Forster R, Kromkamp J (2004) Modelling the effects of chlorophyll fluorescence from subsurface layers on photosynthetic efficiency measurements in microphytobenthic algae. Mar Ecol Prog Ser 284:9-22

Furnas M (2003) Catchments and corals: terrestrial runoff to the Great Barrier Reef. Australian Institute of Marine Science and CRC Reef, Townsville 
Geider RJ, Roche J, Greene RM, Olaizola M (1993) Response of the photosynthetic apparatus of Phaeodactylum tricornutum (Bacillariophyceae) to nitrate, phosphate, or iron starvation. J Phycol 29:755-766

Glud RN, Kühl M, Wenzhoefer F, Rysgaard S (2002) Benthic diatoms of a high Arctic Fjord (Young Sound, NE Greenland): importance for ecosystem primary production. Mar Ecol Prog Ser 238:15-29

Gottschalk S (2005) The response of diatom communities of the Great Barrier Reef to nutrient enrichment. Diplomarbeit, Universität Rostock

Graziano L, La Roche J, Geider R (1996) Physiological responses to phosphorus limitation in batch and steady state cultures of Dunaliella tertiolecta (Chlorophyta): a unique stress protein as an indicator of phosphate deficiency. J Phycol 32:825-838

Hamilton LJ (2001) Cross-shelf colour zonation in northern Great Barrier Reef lagoon surficial sediments. Aust J Earth Sci 48:193-200

Hartig P, Wolfstein K, Lippemeier S, Colijn F (1998) Photosynthetic activity of natural microphytobenthos populations measured by fluorescence (PAM) and ${ }^{14} \mathrm{C}$-tracer methods: a comparison. Mar Ecol Prog Ser 166:53-62

Heil CA, Chaston K, Jones A, Bird P, Longstaff B, Costanzo S, Dennison W (2004) Benthic microalgae in coral reef sediments of the southern Great Barrier Reef. Coral Reefs 23: 336-343

Koop K, Booth D, Broadbents A, Brodie J and 16 others (2001) ENCORE: the effect of nutrient enrichment on coral reefs. Synthesis of results and conclusions. Mar Pollut Bull 42: 91-120

Kromkamp J, Barranguet C, Peene J (1998) Determination of microphytobenthos PSII quantum efficiency and photosynthetic activity by means of variable chlorophyll fluorescence. Mar Ecol Prog Ser 162:45-55

Kühl M, Glud RN, Borum J, Roberts R, Rysgaard S (2001) Photosynthetic performance of surface-associated algae below sea ice as measured with a pulse-amplitude-modulated (PAM) fluorometer and $\mathrm{O}_{2}$ microsensors. Mar Ecol Prog Ser 223:1-14

Lippemeier S, Hintze R, Vanselow K, Hartig P, Colijn F (2001) In-line recording of PAM fluorescense of phytoplanton cultures as a new tool for studying effects of fluctuating nutrient supply on photosynthesis. Eur J Phycol 36:86-100

Pandolfi JM, Bradbury RH, Sal, E, Hughes, TP and 8 others (2003) Global trajectories of the long-term decline of coral reef ecosystems. Science 301:955-958

Perkins RG, Underwood GJC, Brotas V, Snow GC, Jesus B, Ribeiro L (2001) Response of microphytobenthos to light: primary production and carbohydrate allocation over an emersion period. Mar Ecol Prog Ser 223:101-112

Perkins RG, Oxborough K, Hanlon ARM, Underwood GJC, Baker NR (2002) Can chlorophyll fluorescence be used to estimate the rate of photosynthetic electron transport within microphytobenthic biofilms? Mar Ecol Prog Ser 228:47-56

Platt T, Gallegos C, Harrison W (1980) Photoinhibition of photosynthesis in natural assemblages of marine phytoplankton. J Mar Res 687-701

Ralph P, Gademann R (2005) Rapid light curves: a powerful tool to assess photosynthetic activity. Aquat Bot 82:222-237

Ralph P, Gademann R, Dennison W (1998) In situ underwater seagrass photosynthesis measured using a submersible pulse-amplitude-modulated flourometer. Mar Biol 132: 367-373

Ralph P, Gademann R, Larkum A, Schreiber U (1999) In situ underwater measurements of photosynthetic activity of coral zooxanthellae and other reef dwelling dinoflagellate endosymbionts. Mar Ecol Prog Ser 180:139-147

Sartory DP, Grobbelaar JU (1984) Extraction of chlorophyll a from freshwater phytoplankton for spectrophotometric analysis. Hydrobiologia 114:177-187

Schaffelke B, Uthicke S, Klumpp DW (2004) Water quality, sediment and biological parameters at four nearshore reef flats in the Herbert River Region, Central GBR. Research Publication No. 82. Great Barrier Reef Marine Park Authority, Townsville

Schreiber U, Schliwa U, Bilger W (1986) Continuous recording of photochemical and non-photochemical chlorophyll fluorescence quenching with a new type of modulating fluorometer. Photosynth Res 10:51-62

Scoffin T, Tudhope A (1985) Sedimentary environments of the central region of the Great Barrier Reef of Australia. Coral Reefs 4:81-93

Serôdio J (2003) A chlorophyll fluorescence index to estimate short-term rates of photosynthesis by intertidal microphytobenthos. J Phycol 39:33-46

Serôdio J (2004) Analysis of variable chlorophyll fluorescence in microphytobenthos assemblages: implications of the use of depth-integrated measurements. Aquat Microb Ecol 36:137-152

Serôdio J, Da Silva JM, Catarino F (2001) Use of in vivo chlorophyll a fluorescence to quantify short-term variations in the productive biomass of intertidal microphytobenthos. Mar Ecol Prog Ser 218:45-61

Serôdio J, Vieira S, Cruz S, Barroso F (2005) Short-term variability in the photosynthetic activity of microphytobenthos as detected by measuring rapid light curves using variable fluorescence. Mar Biol 146:903-914

Sorokin YI (1993) Coral reef ecology. Springer Verlag, New York

Underwood AJ (1981) Techniques of analysis of variance in experimental marine biology. Oceanogr Mar Biol Annu Rev 19:513-605

Underwood G (2002) Adaptations of tropical marine microphytobenthic assemblages along a gradient of light and nutrient availability in Suva Lagoon, Fiji. Eur J Phycol 37: $449-462$

Uthicke S (2001) Interactions between sediment-feeders and microalgae on coral reefs: grazing losses versus production enhancement. Mar Ecol Prog Ser 210:125-138

Uthicke S, Klumpp DW (1997) Ammonium excretion by holothurians enhances production and turnover in benthic diatom communities. In: Lessios HA, Macintyre IG (eds) Proc 8th Int Coral Reef Symp, Panama, 1:873-876

Uthicke S, Klumpp DW (1998) Microbenthos community production in sediments of a near shore coral reef: seasonal variation and response to ammonium recycled by holothurians. Mar Ecol Prog Ser 169:1-11

van Woesik R, Tomascic T, Blake S (1999) Coral assemblages and physico-chemical characteristics of the Whitsunday Islands: evidence of recent community changes. Mar Freshw Res 50:427-40

White A, Critchley C (1999) Rapid light curves: a new fluorescence method to assess the state of the photosynthetic apparatus. Photosynth Res 59:63-72 